\title{
África do Sul e Brasil: diplomacia e comércio (1918-2000)
}

\author{
PIO PENNA FILHO*
}

\section{Introdução}

O Brasil começou a se aproximar da União Sul-Africana em 1918, com a criação de um Consulado de Carreira na Cidade do Cabo. Embora o primeiro cônsul de carreira só tenha assumido o seu posto em 1926, o gesto do governo brasileiro demonstrou o seu interesse em estreitar as relações comerciais com a União Sul-Africana, ampliando o horizonte do intercâmbio comercial do Brasil com uma região economicamente próspera e estrategicamente significante.

Do ponto de vista estritamente político, as relações entre Brasil e África do Sul foram estabelecidas apenas em 1947-1948, com a abertura, respectivamente, de uma representação diplomática sul-africana no Rio de Janeiro e da Legação brasileira em Pretória. Todavia, essas relações foram marcadas, ao longo dos últimos 45 anos, pela existência de um projeto social que definitivamente excluía as possibilidades de maior aproximação entre os dois povos.

O apartheid, política oficial de segregação racial, ou de desenvolvimento em separado, conforme pregavam seus formuladores, era exatamente o contraponto à sociedade brasileira, que sustentava discurso oficial de democracia racial, convívio harmônico entre as raças e que considerava o fato de o país ser uma nação predominantemente composta por mestiços. Desta forma, seria realmente um paradoxo se as relações entre dois países tão diferentes, sem vínculos históricos e culturais e com um intercâmbio comercial relativamente reduzido, prosperassem com vigor.

Outros fatores certamente influenciaram no cálculo dos formuladores e executores de política externa de ambos os países para moldarem seu relacionamento. No lado brasileiro, houve, ainda durante os anos 1950, a gênese

Rev. Bras. Polít. Int. 44 (1): 69-93 [2001]

* Doutor em História das Relações Internacionais pela Universidade de Brasília (UnB) e Professor da Universidade Federal de Mato Grosso (UFMT). O presente trabalho é baseado na tese de doutorado do autor, Do Pragmatismo Consciente à Parceria Estratégica: As Relações Brasil-África do Sul (19182000), apresentada no programa de doutorado em História das Relações Internacionais da Universidade de Brasília em março de 2001. 
de uma política específica voltada para a então União Sul-Africana, mas que acima de tudo estava consubstanciado no pragmatismo comercial, ou seja, nas possibilidades de auferir vantagens através do comércio com um país aberto a esta perspectiva. Noutro sentido, vale recordar que, na década de 1950, a maior parte do continente africano encontrava-se ainda sob o colonialismo europeu.

Para a União Sul-Africana, a aproximação com o Brasil centrava-se em um cálculo eminentemente político-estratégico, voltado para a inserção internacional daquele país, e não em uma perspectiva comercial. A conjuntura internacional do pós-Segunda Guerra Mundial efetivamente indicava a ameaça de isolamento internacional da União Sul-Africana, o que impeliu Pretória a se aproximar de áreas geográficas até então não exploradas - ou pouco exploradas - e de países que exercessem alguma influência no plano regional e internacional e que eventualmente pudessem prestar-lhe suporte, principalmente na ONU. Tal eram os casos, na América Latina, do Brasil e da Argentina e, em menor grau, do Chile.

A evolução da política externa brasileira vis-à-vis a África do Sul ${ }^{1}$ dependeu de múltiplos fatores para a sua aproximação ou distanciamento. Quando se analisa essa evolução, alguns elementos destacam-se e passam a estruturar e determinar o nível de aprofundamento ou superficialidade entre os dois países, sobretudo quando contemplados seus interesses comerciais e aqueles relativos à política internacional, exercidos nos foros multilaterais mas que inegavelmente refletiam-se no campo das relações bilaterais.

Associada ao fenômeno do apartheid, a questão da ocupação ilegal do Sudoeste Africano (atual Namíbia), por parte da África do Sul, foi o outro elemento que provocou maior atrito nas relações entre os dois países. O Brasil não aceitou a simples anexação do território pretendida pelo governo de Pretória, batendo-se nas Nações Unidas em posição contrária na tentativa de forçar aquele governo a abandonar o território, restaurando o mandato da antiga Liga das Nações sob os domínios da Organização das Nações Unidas. Em última instância, o objetivo da ONU era promover a completa independência da excolônia alemã.

Na verdade, com o avanço do processo de descolonização no continente africano, a política brasileira para a África do Sul seguiu a tendência de contemplar um cenário mais complexo, envolvendo o continente como um todo, o que resultou, em última instância, em maior grau de politização dessas relações.

A inflexão da política africana do Brasil implicava também a mudança de atitude com relação a Pretória. Se até 1974-1975 o governo brasileiro ainda se preocupava em manter discretos laços com Pretória, tendo em mente a manutenção das boas relações comerciais, a partir desse período a tendência 
foi a de abandonar a atitude comercial e a de assumir uma atitude política mais vigorosa e inflexível ${ }^{2}$. Implícito, na transformação da visão do Brasil sobre o seu relacionamento com a África do Sul, estava o cálculo estratégico de relações comerciais e econômicas mais intensas com outros países africanos, o que forçou uma demonstração concreta de que haviam-se operado na política externa brasileira mudanças reais, e não somente vagas declarações oficiais de apoio aos povos africanos em sua aspiração de independência, superação do subdesenvolvimento e luta contra a discriminação racial.

A decisão tomada com relação à África do Sul em meados da década de 1970 conduziu a política externa do Brasil sem substantivas alterações até o final da era africânder. Houve, entretanto, com o fim do regime militar brasileiro, manifestações mais contundentes do país perante a África do Sul. Em 1985, consoante a redemocratização do Brasil, a intensificação da pressão internacional sobre a África do Sul e o recrudescimento interno nesse país contra a maioria negra (por exemplo, estado de emergência, decretado em 1985 pelo governo de P. W. Botha), o governo brasileiro patrocinou decretolei proibindo todas as atividades de intercâmbio cultural e esportivo com a África do Sul, além de reafirmar a proibição de venda ou trânsito de armas em território nacional que se destinassem àquele país. Tal atitude nada mais significou do que o coroamento da decisão anterior de esfriar ao máximo o relacionamento entre os dois países e de respeitar o embargo voluntário de venda de armamentos para a África do Sul, decidido ainda na década de 1960 pelas Nações Unidas e referendado pela decisão do Conselho de Segurança, em 1977, de impor o embargo compulsório de venda e fornecimento de armamentos e similares para a África do Sul. De qualquer maneira, é preciso registrar tal decisão como uma manifestação política demarcatória da fase de isolamento oficial que Brasília estava reafirmando e reforçando contra Pretória.

Após 1985, as relações entre Brasil e África do Sul só serão retomadas em um patamar político de mais alto nível com o fim do regime do apartheid. Ao ser eliminado o regime segregacionista, principal empecilho para a concretização de relações diplomáticas, econômicas e culturais normais entre os dois países, estarão dadas as condições minimamente necessárias para o entendimento e as possibilidades de relacionamento entre Brasil e África do Sul.

No início dos anos 1990, o Brasil, finalmente, designou um embaixador para ocupar a chefia na representação brasileira em Pretória além de, ainda no campo diplomático, ter reaberto o consulado brasileiro na Cidade do Cabo, gestos que simbolicamente representaram o reconhecimento por parte do Brasil da nova realidade sul-africana. Da mesma forma, na mesma década, foi realizada a primeira visita de um chefe de Estado brasileiro à África do Sul (1996), bem como o Brasil recebeu a visita de Nelson Mandela (1991 e 1998) 
e Thabo Mbeki (1997 e 2000), os dois primeiros presidentes negros na história da África do Sul.

O interesse na aproximação entre as duas regiões foi reafirmado em fevereiro de 2000 com a visita do Ministro das Relações Exteriores do Brasil, Luiz Felipe Lampreia, à Cidade do Cabo, onde as conversações acerca da integração econômica foram retomadas. Assim, observa-se que o interesse na aproximação com a África do Sul mantém-se, sendo este um país que passou a ser considerado uma das prioridades para a política externa brasileira no continente africano na década de 1990.

\section{Brasil e União Sul-Africana: o descompasso na aproximação e o comércio como vetor do relacionamento (1918-1947)}

Com efeito, o principal vetor de dinamização das relações entre o Brasil e a União Sul-Africana em todo o período compreendido entre os anos de 1918 e 1947 foi o comércio. Feito de forma irregular e sempre favorável ao Brasil, praticamente não recebeu apoio governamental, em nenhum dos dois lados. Poucas foram as iniciativas emanadas de dentro do Estado - nos dois casos - de se buscar fórmulas para incrementar o intercâmbio. Assim, é sintomático que somente em 1939 tenha sido assinado o primeiro acordo de comércio, envolvendo diretamente as duas partes.

Após a criação do Consulado de Carreira do Brasil na Cidade do Cabo, seguiram-se episódicas tentativas de aproximação, como a iniciativa da Companhia de Navegação Lloyd Brasileiro de estabelecer uma linha mercante direta entre os dois países, em 1922, o que possibilitaria a expansão das relações comerciais; a decisão sul-africana de enviar Alwyn Zoutendyk em missão especial à América do Sul, em 1936, para analisar as perspectivas de comércio e o estabelecimento de uma representação sul-africana no continente; as iniciativas brasileiras de 1938 e 1940 para o estabelecimento de relações diplomáticas, com a criação de uma Legação em Pretória; a assinatura do Acordo Comercial de 1939; o desenvolvimento do comércio e seu vertiginoso crescimento durante a Segunda Guerra Mundial e, finalmente, como coroamento de todas essas iniciativas e as novas mudanças introduzidas nas relações internacionais como conseqüência direta do final da última Guerra Mundial, sobretudo para a União Sul-Africana, a troca de missões diplomáticas no nível de Legação entre os dois países.

Entre as iniciativas brasileiras mais importantes no período compreendido entre os anos de 1918 e 1947, destacaram-se: a) a ida, de forma pioneira e visionária, de uma missão da companhia de navegação Lloyd Brasileiro à União Sul-Africana para estabelecer uma linha mercante ligando diretamente os dois continentes e, ao mesmo tempo, tentar criar condições 
para que o comércio entre os dois países pudesse ser dinamizado; b) a estruturação da rede consular brasileira na África do Sul - e, indiretamente, em toda a região da África Austral - uma vez que os consulados e viceconsulados honorários existentes não estavam capacitados para desenvolver a contento as suas funções, como bem observou e apontou, detalhadamente, Álvaro de Magalhães, o primeiro cônsul de carreira do Brasil na União SulAfricana; c) as gestões brasileiras efetuadas no final dos anos 1930 para estabelecer relações diplomáticas diretas com a União Sul-Africana, decididas pelo Ministro das Relações Exteriores, Osvaldo Aranha; d) o desenvolvimento do comércio e o incremento das exportações brasileiras, as quais atingiram seu ponto máximo, na primeira metade do século XX, durante a Segunda Guerra Mundial, quando Brasil e União Sul-Africana fizeram parte da aliança que derrotou o nazi-fascismo.

A perspectiva da União Sul-Africana mostrou-se bem mais tímida que a brasileira. Vinculados, no plano externo, à Grã-Bretanha, e sobremodo atribulados com suas questões internas, que envolviam desde atritos entre brancos e negros a profundas divergências entre africânderes e britânicos, e entre africânderes e africânderes, geralmente com relação a que tipo de país deveria ser a África do Sul, não é de se estranhar que os dirigentes tivessem dificuldades em controlar as relações externas da União, como se fossem um objetivo de primeiro plano. A América Latina, sobretudo, permanecia à margem de relações que oscilavam entre a Europa e os Estados Unidos durante a maior parte da primeira metade do século XX.

Contudo, mesmo que timidamente, a União Sul-Africana esboçou uma aproximação com a América Latina e, em especial, com o Brasil. À parte algumas iniciativas particulares que se verificaram na década de 1920, em 1936 foi enviada a primeira missão oficial sul-africana à América do Sul com o intuito de estudar in loco as possibilidades comerciais. A missão, confiada ao diplomata Alwyn Zoutendyk, visitou o Brasil, a Argentina e o Uruguai, resultando na recomendação de que a União estabelecesse um Consulado para promover os seus negócios no continente sul-americano, o que proporcionou, pelo lado sul-africano, além do incremento comercial, maior conhecimento da realidade dos países da América do $\mathrm{Sul}^{3}$.

As relações entre o Brasil e a União Sul-Africana somente começaram a tomar corpo durante a época da Segunda Guerra Mundial, conforme demonstra o Relatório do Ministério das Relações Exteriores de 1944, que registrou a nova situação ${ }^{4}$. Nesse contexto, o ponto de ligação estava relacionado ao extraordinário incremento das trocas comerciais entre os dois países $^{5}$, fato motivado principalmente pela conjuntura da Segunda Guerra Mundial, que desestabilizou temporariamente os fluxos tradicionais de comércio, abrindo novas rotas e permitindo certa diversificação de parceiros, o que 
resultou também na abertura de um Consulado da União Sul-Africana na cidade do Rio de Janeiro, em 1943. Contudo, o fato de o Brasil haver aderido à aliança ocidental na Segunda Guerra teve resultados objetivos na aproximação com a África do Sul, sobretudo porque esta vinha desempenhando uma política de desconfiança generalizada para com os Estados indecisos, como era o caso da maioria dos latino-americanos.

Da perspectiva militar e estratégica, a interação entre os setores militares dos dois países foi bastante reduzida, haja vista que, apesar de ambos terem participado diretamente do conflito, enviando tropas, o campo de atuação se deu em teatros de guerra diferenciados. Apesar da falta de contatos mais estreitos no campo militar, registre-se, no entanto, que, quando da chegada da Força Expedicionária Brasileira ao continente europeu, o Comando do Exército sul-africano foi um dos que colaborou para suprir o Exército brasileiro com fardamento apropriado para o severo inverno europeu, para o qual as tropas brasileiras não dispunham de equipamento adequado ${ }^{6}$.

\section{As atividades consulares brasileiras na União Sul-Africana: um balanço}

O consulado brasileiro na Cidade do Cabo desempenhou basicamente duas funções até a criação da Legação em 1947. A justificativa para a existência do consulado baseava-se na representação geral dos interesses brasileiros no sul da África - que na verdade não eram tantos - e, mais especificamente, na promoção do comércio bilateral, que alavancou as relações entre os dois países e abriu caminho para o estabelecimento de relações diplomáticas. Mas, a função mais importante desde 1926, ano em que o primeiro cônsul de carreira brasileiro chegou à Cidade do Cabo até o final da Segunda Guerra Mundial, sem dúvida alguma, foi a de promover o comércio. No entanto, é relevante observar que, embora o fator econômico, na sua vertente comercial, tenha sido essencial para a aproximação do Brasil com a União Sul-Africana, houve um forte e evidente conteúdo político que estimulou a aproximação entre ambos. Tanto é assim que não foi mera coincidência o fato de o Consulado de Carreira e a Legação terem sido criados, na União Sul-Africana, justamente em período imediatamente posterior aos dois conflitos mundiais do século XX, dos quais ambos os países participaram ao lado dos vencedores.

O primeiro acordo comercial assinado entre Brasil e União SulAfricana foi concluído no Rio de Janeiro, por troca de notas, em 18 de abril de 1939. ${ }^{7}$ Antes da assinatura desse acordo, a União Sul-Africana beneficiavase dos acordos comerciais firmados entre o Brasil e a Grã-Bretanha, uma vez que, por ser parte dos Domínios britânicos, a União era incluída como beneficiária direta. Além disso, os representantes diplomáticos e comerciais 
britânicos, em tese, deveriam zelar pelo comércio entre a União e o Brasil, por serem seus representantes legais. Esse quadro só veio sofrer alterações com a designação de Alwyn Zoutendyk como cônsul da União Sul-Africana para os países do cone sul (Argentina, Brasil e Uruguai).

O final dos anos 1930 foi significativo para o intercâmbio comercial entre os dois países. O comércio, que vinha crescendo desde a metade daquela década, sofreu um grande impulso com a eclosão da Segunda Guerra Mundial. Contudo, após atingir o auge, em 1943, houve a tendência ao declínio, embora tenha permanecido em um patamar mais elevado do que no período anterior ao conflito mundial.

Em 1947, o Brasil instalou oficialmente uma Legação diplomática em Pretória, sinal de que havia se consolidado no país um interesse político maior pela aproximação com os sul-africanos ${ }^{8}$. Mas mesmo com a instalação da Legação em Pretória, o consulado na Cidade do Cabo permaneceu em atividade.

\section{A Missão Sul-Africana à América do Sul: o Relatório Zoutendyk (1936)}

Alwyn Zoutendyk foi enviado pelo governo sul-africano, em 1936, para uma visita a três países da América do Sul: Argentina, Uruguai e Brasil. O principal objetivo de sua missão foi elaborar um estudo das possibilidades concretas de se estabelecer uma representação permanente da União SulAfricana no continente sul-americano, com especial atenção para o desenvolvimento e aprofundamento do intercâmbio comercial entre as duas regiões, onde os interesses sul-africanos poderiam não estar sendo bem sustentados.

A análise dos resultados da viagem de Zoutendyk é esclarecedora em muitos aspectos relativos aos contatos comerciais, às possibilidades econômicas, e a visão de um sul-africano sobre aqueles países da América do Sul na primeira metade do século XX. Lança um feixe de luz em questões intrigantes e até certo ponto tão atuais, como o relativo desconhecimento - que persiste até a atualidade - verificado entre os países e algumas das causas do igualmente relativo baixo grau de intercâmbio comercial, bem como dos caminhos que poderiam ser tomados para alavancar o comércio e a aproximação entre Brasil e União Sul-Africana.

Muito embora a Argentina tenha sido o país que mais chamou a atenção da União Sul-Africana na América do Sul nos primórdios do relacionamento entre aquele país e este continente, sobretudo pela presença bôer na Argentina e por iniciativas pessoais de autoridades sul-africanas, foi o Brasil que mais impressionou a Zoutendyk. A própria elaboração do seu relatório possibilita uma idéia geral e comparativa das primeiras impressões e das possibilidades 
comerciais observadas por seu autor: das onze páginas do detalhado relatório, quase sete páginas são dedicadas ao estudo dos principais aspectos econômicos do Brasil que diretamente interessariam à União Sul-Africana, restando apenas quatro páginas para as análises relativas à Argentina e ao Uruguai ${ }^{9}$.

Foi somente na viagem de 1918, portanto a sua segunda à América do Sul, que Zoutendyk visitou o Brasil. O tempo de permanência foi curto - um mês - mas o suficiente para que pudesse ter uma idéia geral do perfil da economia brasileira e dar início às primeiras prospecções sobre as relações entre os dois países. A sua breve estada no Brasil se deve, por um lado, ao entusiasmo inicial pela Argentina, que o levou a permanecer mais tempo naquela nação, mas por outro lado também contou a vontade de aprofundar os seus conhecimentos sobre a América do Sul, em um contexto em que seria muito natural a visita a outros países. Quando Zoutendyk voltou ao Brasil, em 1936, já possuía, portanto, uma idéia do país.

Apesar de sua atração pessoal pela Argentina, na viagem de 1936 Zoutendyk ficou animado com os progressos que, em sua opinião, o Brasil havia feito em termos de desenvolvimento econômico desde sua visita 18 anos antes. Em seu relatório para o Departamento de Negócios Estrangeiros da União Sul-Africana, fez uma análise extremamente positiva e promissora para o relacionamento comercial entre os dois países. Segundo suas perspectivas, a União Sul-Africana poderia ter sucesso no comércio com o Brasil exportando pelo menos 10 produtos, a saber: carvão, frutas frescas não tropicais (como maçã, uva, pera, ameixa e nectarina), frutas secas, geléias, brandy, gim, vinhos, tabaco (tipo turkish), lagostas e peixe seco. Em contrapartida, poderia a União importar pelo menos os seguintes produtos: café, arroz, madeiras (dormentes para ferrovias, madeiras para emprego no importante setor minerador sulafricano, para a construção civil, confecção de caixas para exportação de frutas e móveis), peças de vestuário, seda, papel, vidro (cristal e comum) e garrafas para todo tipo de emprego ${ }^{10}$.

Além da relativa variedade de produtos possíveis de intercambiar, o enviado sul-africano destacou as vantagens propiciadas pela proximidade entre os dois países ("metade da distância entre a União Sul-Africana e a Europa ou os Estados Unidos”) o que, em tese, permitiria a prática de menor valor no frete das mercadorias. Outro aspecto destacado por ele era o fato de que o Brasil "manufatura praticamente tudo em grande escala", o que o tornava apto a competir em qualquer mercado do mundo. Por sua vez, a União SulAfricana tinha muito a oferecer ao Brasil, com disponibilidade de vários produtos e com preço e qualidades competitivos. Na visão de Zoutendyk, que demonstrou possuir ampla percepção mercadológica, associada a um grande otimismo que não se verificou de forma concreta, ambos os países estavam perdendo tempo e dinheiro ao deixarem-se levar pela ignorância mútua ${ }^{11}$. 
De acordo com Zoutendyk, os dois produtos sul-africanos que tinham mais chance de alcançar o mercado brasileiro eram o carvão e as frutas. Para o carvão, os dados levantados pelo agente sul-africano indicavam que o Brasil, pela sua escassa produção, necessitava de 3 a 4 milhões de toneladas por ano para abastecer suas ferrovias, navios, fábricas e companhias de gás e que, em suas entrevistas com engenheiros e gerentes de algumas dessas empresas, todos mostraram-se interessados no carvão de seu país, sendo que ele ainda observou a completa ignorância por parte daquelas pessoas acerca do fato de a União possuir grandes reservas do mineral.

Embora tenha pensado em uma representação única para os países latino-americanos, Zoutendyk, até onde a documentação encontrada informa, foi pioneiro ao propor o estabelecimento de uma Legação diplomática sulafricana na América Latina e, no caso do Brasil, antes mesmo das iniciativas do governo brasileiro, as quais tiveram início em 1938, sob o patrocínio de Osvaldo Aranha. Naturalmente que o que motivava o enviado sul-africano não eram os temas políticos, praticamente inexistentes, mas sim as matérias de cunho comercial que poderiam ser agilizadas, uma vez que a União pudesse contar com representação própria na América do Sul.

\section{A aproximação diplomática: o Brasil toma a iniciativa}

Coube ao Brasil a iniciativa de tentar se aproximar politicamente da União Sul-Africana, propondo o estabelecimento de relações diplomáticas diretas através da criação de uma Legação brasileira em Pretória e da correspondente contrapartida sul-africana abrindo uma Legação no Rio de Janeiro.

A abordagem inicial foi feita no Rio de Janeiro, em maio de 1938, pelo recém-indicado Ministro das Relações Exteriores, Osvaldo Aranha, ao embaixador Hugh Gurney, da Grã-Bretanha. A princípio, a argumentação de Aranha baseava-se no fato de que as perspectivas de incremento comercial eram boas e que ambos os países - assim como o Canadá, outro país incluído na conversa entre Aranha e Gurney - tinham "mentalidade similar”, isto é, eram nações que valorizavam a democracia ${ }^{12}$.

Dando seqüência ao assunto, o Alto Comissário para o Reino Unido procedeu, então, a consultas informais a Pretória a fim de identificar o ponto de vista do governo da União Sul-Africana a respeito da intenção brasileira de abrir uma Legação em Pretória. A resposta sul-africana foi rápida e negativa. Em menos de vinte dias após a consulta, P. R. Botha, Secretário do Department of External Affairs sul-africano, escreveu ao Alto Comissário do Reino Unido, M.E. Antrobus, informando-o de que, se por um lado, a criação de uma Legação brasileira em Pretória seria bem vinda, por outro, destacava que também seria 
natural que o Brasil esperasse a reciprocidade do ato, para o qual a União SulAfricana não estaria ainda preparada e nem haveria como indicar sequer uma provável data para que tal pudesse vir a ocorrer. O único aspecto concreto era que o governo da União havia enviado um emissário especial como seu representante para a América do Sul, em 1936, com a missão de avaliar as possibilidades de estreitamento das relações entre a União e os países da região, especificamente com o Brasil, Argentina e o Uruguai. Dessa forma, a missão enviada à América do Sul tinha por objetivo efetuar estudos das possibilidades comerciais existentes e de verificar se se justificava ou não a criação de representação - ou representações - diplomática sul-africana permanente naquela região ${ }^{13}$.

Do ponto de vista de Pretória, a idéia de aprofundar o relacionamento com o Brasil - e, no geral, com os países sul-americanos - seguia uma lógica diferente. O comércio, certamente, não era o elemento mais importante para os sul-africanos, haja vista que as suas exportações para o Brasil nunca foram expressivas. Todavia, do ponto de vista político, era altamente recomendável para o governo da União estabelecer vínculos com os países do continente sul-americano.

Foi somente durante o primeiro semestre de 1947 que as autoridades sul-africanas de fato consideraram a idéia de estabelecer relações diplomáticas com os países sul-americanos. Tal atitude esteve estreitamente relacionada com a conjuntura política internacional e com a pressão que o governo da União vinha sofrendo no âmbito da Nações Unidas. Mas, além disso, os ingleses também desempenharam um papel na aproximação entre a União Sul-Africana e a América Latina. Como bem salienta Schellnack, ao final da Segunda Guerra, enfraquecidos pela longa duração do conflito e sendo suplantados pelos Estados Unidos no comércio internacional, os britânicos tentaram animar as relações comerciais diplomáticas envolvendo a América Latina e as várias partes do Império, principalmente distribuindo relatórios favoráveis ao comércio com os países latino-americanos, numa derradeira tentativa de manter as relações preexistentes. Assim, o seu papel foi principalmente o de estimular Pretória a buscar esse relacionamento, exatamente pensando em aumentar o comércio e a encontrar alternativas para ampliar o leque das possíveis alianças da União no contexto das Nações Unidas ${ }^{14}$.

\section{As relações diplomáticas: o jogo dos opostos (1947-1974)}

O final da Segunda Guerra Mundial significou, para as relações entre o Brasil e a União Sul-Africana, um período de renovação e um marco nas relações bilaterais, tal qual havia acontecido ao final da Primeira Guerra, quando o Brasil abriu o Consulado de Carreira na Cidade do Cabo. Aliados, durante o conflito, as 
perspectivas para as relações bilaterais apresentavam-se de forma positiva. No plano comercial, houve, durante a década de 1940, um crescimento extraordinário das trocas comerciais, levando o Brasil grande vantagem; na perspectiva política, a projeção alcançada pela União, sobretudo pela marcante presença internacional de seu Primeiro Ministro, Jan Smuts, redobrou o interesse brasileiro em se aproximar daquele país, interesse este que datava do final dos anos 1930, quando o então Ministro das Relações Exteriores, Osvaldo Aranha, manifestou o interesse do Brasil em se aproximar da União, com o desejo de abrir uma Legação em Pretória.

Além do interesse nos fatores econômicos, é preciso levar-se em conta que outros elementos contribuíram decisivamente para a iniciativa do governo Dutra em abrir aquela Legação, destacando-se, no caso, o fato de a União Sul-Africana ser um dos poucos países independentes do continente africano e de ser considerado um aliado ocidental inconteste no confronto bipolar que já se vislumbrava no horizonte das relações internacionais do pós-Segunda Guerra Mundial ${ }^{15}$. Há ainda que mencionar que desde o ano de 1943 o governo da África do Sul já se fazia representar no Rio de Janeiro através de um Consulado Geral, mais tarde elevado à categoria de Legação Diplomática, o que de certa maneira incentivava o Brasil a instalar uma Legação naquele país, entrando também no cômputo da decisão o fator reciprocidade.

Outro fator estimulante para que os sul-africanos encetassem relações com o Brasil estava ligado à expansão das relações exteriores da União Sul-Africana que, efetivamente, eram muito modestas. Saliente-se que até o final dos anos 1940 a União se fazia representar, entre a Europa e a América, somente em 11 países, a saber: Holanda (1929), Estados Unidos (1929), Itália (1929), Portugal (1934), Bélgica (1934), França (1934), Alemanha (1934), Suécia (1934), Canadá (1938), Argentina (1938) e Brasil (1943). Na África e na Ásia, as representações da União se resumiam a um Consulado Geral em Moçambique (1920), um Comissariado de Comércio para a África Ocidental e do Norte, estabelecido no Marrocos (1938), Escritórios de Representação Comercial em Cingapura e na Índia e Comissários Honorários de Comércio na Palestina e na China. Há ainda a ressaltar o fato de que, durante a Segunda Guerra, e motivado pela sua conjuntura específica, o governo da União abriu missões no Congo Belga, em Madagascar e no Egito $(1942)^{16}$.

Do ponto de vista da União, diferentemente da perspectiva assumida pelo Itamaraty, a diplomacia sul-africana percebia o Brasil não como um parceiro comercial importante, mas sim como um eventual aliado político que poderia ajudar a romper a crítica à política racial sul-africana e a possibilidade de isolamento crescente contra a União verificada no interior da Organização das Nações Unidas.

Em decorrência da abertura proporcionada pela II Guerra Mundial, houve a perspectiva, muito embora frustrada, de que haveria possibilidade de o comércio e as relações entre os dois países entrar em ritmo constante e mais acelerado. No 
entanto, com o fim do conflito e a reestruturação da economia internacional, Brasil e União Sul-Africana retomaram seus fluxos de comércio com as tradicionais áreas reassumindo as posições anteriores ${ }^{17}$, o que praticamente encerrou 0 relacionamento que vinha se destacando no cenário atípico das relações comerciais causados pelo efeito da guerra.

De qualquer forma, é importante notar que o Brasil esboçou uma política de relacionamento com a União Sul-Africana, centrando-se fortemente nos aspectos comerciais, sem sobrevalorizar os aspectos geopolíticos, os quais, embora devam ser levados em conta, jamais foram cruciais para o relacionamento entre os dois países, pelo menos do ponto de vista brasileiro. Desta maneira, observa-se uma linha de continuidade com o período anterior que, como discutido, foi essencialmente motivado pelo aspecto comercial.

A análise da influência da geopolítica na execução da política externa brasileira merece uma abordagem específica, dado que o Brasil atravessou uma fase na qual os militares assumiram o poder e deram azo, alguns deles, aos princípios da geopolítica, tanto em sua vertente territorial quanto naval. Com efeito, elementos de geopolítica despertaram algum interesse em setores das forças armadas brasileiras, sendo que, no caso específico das relações com a África do Sul, mais acentuadamente na Marinha, a qual intentou concretizar senão uma aliança militar tendo em mente a defesa do Atlântico Sul, pelo menos um acordo de cooperação militar, do qual o primeiro passo para sua efetivação seria o intercâmbio de informações sobre movimentos navais na área do Atlântico Sul. Tendo sido inicialmente uma proposta vinda de Pretória, no âmbito da outward policy do governo Voster, a Marinha brasileira, de imediato, demonstrou interesse, porém, como o Itamaraty possuía ponto de vista diferenciado sobre o assunto, conseguiu neutralizar a ação sul-africana e evitar o plano da Marinha do Brasil em aceitar o esquema proposto pela África do Sul, que afinal não passou do plano das intenções (e de uma agitada movimentação diplomática, que envolveu representantes brasileiros em Pretória, Buenos Aires, Washington, Londres e Nova York), embora o Ministério da Marinha tivesse chegado, inclusive, a iniciar entendimentos com oficiais sul-africanos na base naval de Simonstown ${ }^{18}$.

Chama atenção também o fato de o Brasil haver esboçado primeiro uma política voltada para a União Sul-Africana enquanto país destacado no continente africano, sem levar em consideração, no período inicial desse relacionamento, o pensamento de uma política externa orientada e dirigida para o continente como um todo. Enquanto persistiu o colonialismo e enquanto os novos países africanos ainda lutavam para obter uma mínima estruturação e participação na política mundial, foi possível ao Brasil conduzir relações específicas com a União Sul-Africana. Contudo, com o avanço da descolonização e a crescente complexidade da realidade africana, mormente na ampla região da África Austral, tornou-se inviável a continuidade desse tipo de relacionamento. 
Paradoxalmente, o período compreendido entre os anos de 1947-1948 e 1974-1975 representou o auge e, ao mesmo tempo, o declínio das relações bilaterais entre o Brasil e a União Sul-Africana. Paulatinamente, as agendas externas dos dois mais importantes países de suas respectivas áreas continentais foram se revelando divergentes e, em alguns casos, mesmo excludentes.

\section{O esgotamento do pragmatismo consciente: o Brasil se afasta e pressiona a África do Sul (1975-1991)}

O período compreendido entre meados da década de 1970 e o final dos anos 1980 é caracterizado pelo quase congelamento das relações bilaterais entre Brasil e África do Sul, as quais atingiram seu nível mais baixo desde a troca de missões diplomáticas em 1947. Assim, houve o esvaziamento da pauta política, que passou a ser de confrontação, com o Brasil assumindo as críticas ao regime sul-africano com total desenvoltura.

Uma vez concretizadas as independências das colônias portuguesas e removida definitivamente a incômoda presença do sistema colonial português, o Brasil pôde, enfim, desencadear uma política mais agressiva no continente africano. Para tanto, foi necessário, igualmente, tomar uma atitude mais coerente nas suas relações com Pretória.

A decisão de se afastar de Pretória e encerrar a contradição da política exterior do Brasil para o continente africano foi tomada no bojo da descolonização das áreas coloniais portuguesas. Mas não só isso explica o afastamento com relação à África do Sul. A diplomacia brasileira já vinha sentindo o peso desse relacionamento, uma vez que a comunidade internacional e, sobretudo, os países afro-asiáticos, acompanhavam pari passu todos os episódios e conexões envolvendo o regime sul-africano.

O Brasil já havia sofrido pressão por parte de Estados africanos, da Liga Árabe, dos asiáticos e do bloco socialista, os quais identificavam a posição brasileira frente à África do Sul como sendo basicamente a mesma dos países da Europa Ocidental e dos Estados Unidos, ou seja, criticava o regime mas mantinha expressivos vínculos comerciais e, como suspeitavam, tinha até mesmo um secreto envolvimento militar com Pretória, consubstanciado na idéia da Organização do Tratado do Atlântico Sul-OTAS ${ }^{19}$.

Assim, para que a política africana do Brasil obtivesse um grau adequado de coerência era preciso rever o relacionamento com a África do Sul. O Itamaraty, desde a intensificação da ação diplomática sul-africana e o lançamento da idéia da OTAS, na segunda metade da década de 1960, já vinha praticando uma política discreta com relação a Pretória, cuja definição mais apropriada era a de um pragmatismo consciente, ou seja, havia, por parte da diplomacia brasileira a exata compreensão que as relações com a África do Sul tinham sua razão de ser 
exclusivamente nas vantagens econômicas que o país obtinha do intercâmbio comercial.

O Brasil procurou moldar o relacionamento com Pretória através da discrição, com o mais baixo grau possível de contatos políticos, e da manutenção e expansão das relações comerciais, em um contexto em que a África do Sul era responsável por mais de $90 \%$ das exportações brasileiras para o continente africano. Mas este quadro estava sofrendo alterações no início da década de 1970, com a decisão brasileira de conquistar novos mercados no continente africano. Disso resultou a visita do Ministro das Relações Exteriores, Gibson Barboza, a vários países africanos no início dos anos 1970 como o primeiro passo concreto para a redefinição das prioridades brasileiras no continente.

A deterioração da imagem sul-africana perante a comunidade internacional, através da permanência dos mesmos problemas - ocupação ilegal do Sudoeste Africano, questão do apartheid, desestabilização dos países da África Austral foi tornando sua situação internacional insustentável. O fim da década de 1970 viu a África do Sul alinhada quase que somente com Estados isolados na comunidade internacional, via de regra, acusados pelo desrespeito sistemático dos direitos humanos. No continente africano, a África do Sul optou, após a descolonização angolana, por endurecer o jogo com os Estados vizinhos, ampliando e sistematizando a política de desestabilização, a qual possuía estratégias diversas, indo da pressão econômica à sabotagem militar.

Assim, quase ao mesmo tempo em que o governo angolano era reconhecido pelo governo brasileiro, a África do Sul patrocinava a invasão de Angola com tropas regulares e dava prosseguimento a suas atividades de suporte à UNITA. Como o Brasil havia optado por uma aproximação especial com os novos países de expressão portuguesa na África, a agressão sul-africana a Angola contribuiu ainda mais para que as relações entre os dois países se deteriorassem.

Dentre as medidas tomadas pelo governo brasileiro para reduzir ao máximo suas relações com a África do Sul, destacavam-se: a) a decisão de desestimular o comércio bilateral, retirando-se o governo de qualquer participação neste sentido; b) dificultar a concessão de vistos para a entrada no Brasil de personalidades sulafricanas, especialmente de funcionários de empresas estatais ou do setor privado (o objetivo desta medida era reforçar o desestímulo à promoção comercial); c) monitorar os investimentos sul-africanos no Brasil, especialmente os que pudessem dar uma conotação de sociedade entre sul-africanos e o governo brasileiro; d) reduzir ao máximo os contatos culturais, desencorajando iniciativas de artistas e desportistas brasileiros que desejassem se apresentar em solo sul-africano; e) estabelecer estrito controle sobre as exportações de armas para a África do Sul, se possível efetivamente proibindo que produtos brasileiros dessa natureza atingissem o mercado sul-africano, tendo em vista não permitir que se levantassem suspeitas sobre o país nesse campo ${ }^{20}$; f) desestimular qualquer iniciativa no campo 
da cooperação técnica; g) intensificar as críticas, no âmbito das Nações Unidas, contra o apartheid e contra a ocupação ilegal da Namíbia.

Na contramão da tendência à redução das relações bilaterais apresentadas pelo Brasil, estava a idéia do Ministério dos Negócios Estrangeiros da África do Sul, que desejava, antes, a intensificação das relações. Desta forma, o Secretário de Assuntos Externos, J. Van Dalsen, no início de 1975, orientava a Embaixada sul-africana em Brasília a buscar renovar as relações com o Brasil, "por várias razões, dentre as quais por sua posição de proeminência econômica no hemisfério, nossas relações com o Brasil precisam assumir um caráter prioritário”21. Todavia, o Brasil caminhava noutro rumo.

A embaixada sul-africana em Brasília, convencida de que no plano oficial nada conseguiria, passou a atuar de maneira independente, mantendo contatos diretos com governos estaduais e empresas privadas interessadas em fazer o comércio com a África do Sul ou obter cooperação técnica em setores nos quais os sul-africanos estavam adiantados. Outra atividade que a embaixada sul-africana exerceu intensamente nos anos de distanciamento oficial foi a prática rotineira de contatos com a imprensa brasileira. Com relativa freqüência, os diplomatas sulafricanos, dentre eles o próprio Embaixador, esforçavam-se por responder a eventuais críticas contra o regime do apartheid ou a estimular a propaganda oficial do seu país, inclusive convidando jornalistas brasileiros para visitas à África do Sul.

O caso mais grave da ação da diplomacia sul-africana no Brasil, contudo, recaiu nas gestões que foram feitas junto a alguns governos estaduais. Os sulafricanos ofereceram, por exemplo, ao governo do Paraná cooperação para o desenvolvimento de fontes alternativas de energia, utilizando-se o carvão para dele extrair petróleo, com uma tecnologia desenvolvida pela estatal sul-africana $\mathrm{SASOL}^{22}$. O problema residia no fato de que essas ações eram efetuadas sem o conhecimento ou o consentimento do Itamaraty, o que acabava por gerar um atrito entre o MRE e a embaixada sul-africana.

\section{Época de possibilidades: a construção da parceria estratégica entre Brasil e África do Sul na última década do século (1991-2000)}

A última década do século XX mostrou-se favorável para o relacionamento entre o Brasil e a África do Sul. Removido o apartheid, principal empecilho para a normalização das relações entre os dois países, ambos buscaram, a princípio timidamente e ao avançar a década com um pouco mais de desenvoltura, resgatar um relacionamento antigo, porém pontuado por restrições de cunho político que mais colaboraram para o afastamento e a permanente condição de desconhecimento mútuo, apesar do caráter de vizinhança atlântica, como bem acentuou o diplomata sul-africano Alwyn Zountendyk na longínqua década de 1930. 
Animado pela perspectiva de solução pacífica e democrática para o problema do apartheid, e considerando a importância econômica que a África do Sul representava (e representa) no continente africano, o Brasil teve todo o interesse em normalizar suas relações com Pretória, tão logo as circunstâncias políticas internas sul-africanas o permitiram.

O contexto político da África Austral era dos mais promissores no início da década de 1990, apresentando um cenário positivo que não era visto desde a época da descolonização. Havia fortes indícios de que a guerra em Angola estava por findar, com eleições marcadas para 1992. Moçambique atravessava uma fase de pacificação política e transição econômica, da economia socialista para o livre mercado. A Namíbia obtivera, em 1990, a independência. A África do Sul, o principal responsável pela situação de insegurança regional, estava comprometida com um processo irreversível de acomodação interna, cujo objetivo último era a democratização de sua sociedade.

A visita de Mandela ao Brasil, em 1991, foi um sinal de que o país despertava, pelo menos entre a liderança do Congresso Nacional Africano, algum interesse, embora nunca tenha sido considerado como prioridade para a política exterior da África do Sul. A boa vontade do governo sul-africano e a estratégia de revigoramento das relações sul-sul, no entanto, motivaram Pretória a incluir a América Latina na sua agenda externa.

Em sua abertura extracontinental, a verdadeira situação de caos econômico e social que parece não ter fim no continente africano, salvo poucas exceções, é um dos fatores que mais colaboram para que a África do Sul busque alternativas ao contexto africano. Desta forma, há movimentos de Pretória que buscam associações ou acordos comerciais com a União Européia, com os Estados Unidos, com a Ásia-Pacífico, com países banhados pelo oceano Índico (no que resultou a criação, em março de 1997, da Associação dos Países da Margem do Índico -Indian Ocean Rim - ${ }^{23}$ e, também, com a América Latina, não sem propósito enumerada em último lugar), tendo no Brasil a porta de entrada para uma eventual associação com o Mercosul, ou mesmo para a criação de uma Associação do Atlântico Sul, que poderia ser elaborada nos moldes da celebrada com os países da margem do Índico, inclusive aproveitandose da estrutura já em funcionamento da Zona de Paz e Cooperação do Atlântico Sul (ZPCAS) ${ }^{24}$.

No plano multilateral existem amplas possibilidades de atuação coordenada, haja vista a notável convergência de interesses. Um desses campos está relacionado com o tema do comércio internacional. A argumentação junto à OMC contra a política de subsídios praticada pela União Européia seria um deles. A reforma das regras de comércio internacional, incluindo-se a reestruturação da própria Organização Mundial do Comércio é outro exemplo 
de como há espaço e necessidade de atuação coordenada para se atingir objetivos difíceis no âmbito da temática do comércio internacional. O Brasil, em sua disputa com o governo do Canadá envolvendo a política brasileira de financiamento à exportação, tem experimentado como as regras do jogo foram construídas para beneficiar os países mais desenvolvidos. Noutros foros, podese e deve-se trabalhar conjuntamente a proposta de controle dos fluxos financeiros internacionais, principalmente os fluxos de capital de curto prazo, assunto que prejudica as economias de ambos, sobretudo por conta da extrema volatilidade do capital financeiro e especulativo.

Ademais, há perspectivas no campo da cooperação bilateral, pois existem especializações complementares. Assim, pode-se citar os seguintes exemplos: a África do Sul detém tecnologia de ponta no setor minerador, podendo contribuir significativamente com o Brasil, seja através de programas oficiais de intercâmbio, como o envio de técnicos brasileiros para cursos de especialização em universidades e centros de pesquisa sul-africanos, ou mesmo para o desenvolvimento de estágios em companhias mineradoras, como já ocorre (porém em escala ainda diminuta), seja através da transferência de tecnologia e por investimentos diretos no Brasil, exemplificado pelo conglomerado sul-africano de mineração Billinton, que adquiriu uma participação acionária de 2,1\% da Companhia Vale do Rio Doce pelo valor de US\$ 327 milhões, como anunciado em julho de $2000^{25}$.

O Brasil, por seu turno, tem valiosa contribuição a oferecer para a África do Sul em termos de cooperação bilateral, especialmente no campo da saúde pública. A África do Sul é um dos países mais atingidos pela epidemia de AIDS no continente africano, que por sua vez detém a triste marca de possuir cerca de $2 / 3$ do total dos seres humanos infectados ${ }^{26}$. Neste sentido, aproveitando-se da experiência adquirida pelo Brasil no combate à AIDS, e lembrando que o país transformou-se em um exemplo para a comunidade internacional por sua iniciativa contra a doença, já está em andamento a discussão em torno da cooperação neste setor. Em 1999, uma missão técnica da Coordenação Nacional de Doenças Sexualmente Transmissíveis (DST/ AIDS), do Ministério da Saúde, visitou a África do Sul e constatou que, em três áreas, há grande possibilidade de cooperação: vigilância epidemiológica, informação em saúde e informação ao público, educação e comunicação (IEC). Ainda nesta área, o Brasil também ofereceu às autoridades sul-africanas tecnologia para produção de AZT em laboratórios do país, o que ajudaria consideravelmente no esforço de combate à doença, com evidentes implicações para a economia sul-africana como um todo ${ }^{27}$. Existem também outras iniciativas no campo da cooperação bilateral que poderiam ser aproveitadas mutuamente. Em setores como a agricultura e recursos humanos, por exemplo, já existem projetos em andamento ${ }^{28}$. 
Assim, delineia-se um quadro amplamente satisfatório para os dois países, haja vista que a natureza da cooperação bilateral pode ser estabelecida em bases igualitárias, em um genuíno exercício de cooperação sul-sul, sem os esquemas tradicionais de dependência que se verificam nas relações nortesul, até mesmo quando esta se apresenta com a roupagem da cooperação.

\section{Conclusão}

A história das relações Brasil-África do Sul apresenta mais momentos de desencontros do que de encontros. Países com perfil econômico semelhante, com estrutura social complexa e formação histórico-cultural diferenciada, os dois Estados mais importantes dos seus respectivos continentes fizeram, ao longo do seu processo de desenvolvimento, opções políticas diferentes. Assim, com a complexidade crescente das relações internacionais, a inserção internacional de ambos se deu de maneira diversa. Enquanto o Brasil buscou inserir-se positivamente no contexto internacional e regional, acatando as regras - nem sempre codificadas - estabelecidas pela ordem internacional, a África do Sul assumiu uma postura de desafio, inserindo-se, pois, de forma negativa, em um processo que chegou ao ápice em meados dos anos 1980, quando o cerco internacional se fechou sobre Pretória, ajudando, e muito, na revisão do anacronismo da política de segregação racial adotada pelos africânderes. Política esta que se chocava, frontalmente, com aquela defendida pela diplomacia brasileira, que valorizava os elementos multirraciais de sua formação étnica.

A ausência de elementos de cunho notadamente histórico convergentes, assim como de aspectos culturais afins, colaborou significativamente para que não houvesse o aprofundamento dos contatos entre os dois povos. O comércio foi o elemento mais importante para manter o interesse brasileiro pela África do Sul e, até certo ponto, desta pelo Brasil, sobretudo na primeira metade do século XX. Ressalte-se, igualmente, que uma característica importante do comércio bilateral foi a proeminência dos negócios privados, que puderam contar muito pouco com a assistência estatal, quadro permanente e que perdura até os dias atuais.

O apartheid teve implicações de toda natureza para a vida sul-africana, seja no plano interno, seja no campo internacional. E teve também implicações para as relações entre o Brasil e a África do Sul. Com efeito, os dois países desenvolveram princípios de política racial diametralmente opostas. Enquanto o governo de minoria branca na África do Sul erigia o apartheid, a sociedade brasileira tornava ilegal a discriminação racial, embora seja necessário reafirmar que isto não significa que, no Brasil, a discriminação racial tenha desaparecido ao toque mágico de uma lei. É por demais evidente que o Brasil, 
apesar da legislação anti-racista, não concretizou nenhuma política racial que tenha tornado possível, à sua numerosa parcela de negros e mestiços, condições de ascensão social.

A grande preocupação do Itamaraty centrava-se em dois aspectos: a) os prejuízos que adviriam para a imagem do Brasil na cena internacional, sobretudo no seio das Nações Unidas, em razão de relações próximas com a pátria do apartheid; daí o adiamento, até o último momento, da elevação da Legação para Embaixada em Pretória, o que só ocorreu em virtude de reformas internas e de caráter administrativo no Itamaraty que, finalmente, decidiu suprimir todas as remanescentes legações; b) uma vez decidida a aproximação com a África negra, fez-se mais do que necessário estabelecer o mais baixo perfil possível nas relações com a África do Sul. Assim, o Brasil, muito embora não tenha rompido relações, como era desejo da maioria dos países africanos, desestimulou ao máximo as relações comerciais com Pretória e não enviou um Embaixador para o posto, demonstrando com este gesto a sua decisão de congelar as relações bilaterais, política reforçada pelo desestímulo de todo tipo de contato oficial em qualquer nível.

Outro aspecto relevante da conduta do Itamaraty com relação à África do Sul foi a sua coerência em termos de conduta política. Desde o final da Segunda Guerra Mundial, quando entrou em discussão nas Nações Unidas a questão do Sudoeste Africano, o Brasil deixou claro sua posição contrária a qualquer tentativa de anexação do território por parte da então União SulAfricana. O entendimento do governo brasileiro era condizente com o sentimento geral que prevalecia na ONU, qual seja: a África do Sul tinha um mandato de administração concedido pela Liga das Nações, o qual passou a ser de responsabilidade direta das Nações Unidas, uma vez criado este organismo internacional como sucessor da antiga Liga. Esta idéia prevaleceu como um princípio para o Itamaraty, o qual, ao longo dos anos, intensificou suas críticas à ocupação ilegal do território por parte de Pretória, principalmente após a aprovação da Resolução 435 (1978) do Conselho de Segurança das Nações Unidas.

Nesse mesmo contexto da coerência da política externa brasileira para a África do Sul, esteve a questão do apartheid. Muito embora o Brasil tenha tomado, a princípio, a questão como sendo um caso de política interna, não sendo, pois, da alçada das Nações Unidas se intrometer, a posição brasileira gradualmente evoluiu para uma postura crítica, alimentada inclusive pela inflexibilidade do governo africânder que se recusava a aceitar as críticas da comunidade internacional e a proceder, até mesmo, a reformas do sistema de discriminação racial. Assim, para a projeção internacional do Brasil, o apartheid passou, de elemento inibidor e constrangedor, para uma variável proibitiva para a política exterior brasileira, sobremodo, àquela voltada para o continente 
africano. Com o avanço e consolidação da política africana brasileira, a partir de meados da década de 1970, o Brasil passou a intensificar, ao máximo, a sua contundente crítica à discriminação racial praticada na África do Sul, feita em todas as oportunidades que se apresentaram, principalmente nas declarações conjuntas elaboradas durante os contatos com os países africanos e nos debates ocorridos nas Nações Unidas.

Nos anos 1990, o Brasil acompanhou a retomada da aproximação com a República da África do Sul, comportamento semelhante àquele adotado pela maior parte dos países do Ocidente. A África do Sul passou, portanto, a ser vista pelo governo brasileiro como possível aliada no plano multilateral - numa época de globalização e incertezas variadas - e parceira importante no plano do comércio bilateral.

Considerando a difícil situação da África Austral, o Itamaraty vem desenvolvendo uma política de atracão da República da África do Sul para entendimentos bilaterais, caso não seja possível um acordo entre o Mercosul e a SADC, ou mesmo entre o Mercosul e a África do Sul. Além do convite para que o Presidente Nelson Mandela participasse da reunião do Mercosul, em 1998, o ex-Ministro das Relações Exteriores do Brasil esteve, no início de 2000, na Cidade do Cabo, para conversações com autoridades sul-africanas a respeito de um projeto de integração econômica, o que demonstra que há interesse por parte do Brasil em intensificar as relações comerciais com a África do Sul, a qual vem sendo considerada pelo MRE, na década de 1990, como um dos três países prioritários para a política externa brasileira no continente africano (sendo os outros dois países Angola e Nigéria).

Com relação à política exterior sul-africana na última década do século $\mathrm{XX}$, o seu estudo permite concluir que o Brasil está longe de ser uma de suas prioridades. A normalização das relações internacionais da África do Sul exigiu um hercúleo esforço dos seus dirigentes, que em muitos aspectos não estavam preparados para assumir tantas responsabilidade a um só tempo. De repente, o Ministério dos Negócios Estrangeiros da África do Sul se viu na contingência de atender inúmeros pedidos de estabelecimento de relações diplomáticas, assim como ser integrado (ou reintegrado) em vários organismos internacionais. Do ponto de vista administrativo, ainda durante o ano de 2000, estava o Ministério passando por uma série de transformações e de ajustes internos, relacionados à transição democrática e à conseqüente necessidade de renovação dos quadros diplomáticos, com a ascensão dos negros aos postos proeminentes.

No que diz respeito às relações entre Brasil e África do Sul desde a democratização da sociedade sul-africana e sua reintegração à comunidade internacional, um dos campos mais propícios para uma eventual cooperação 
entre ambos localiza-se na arena multilateral, onde os dois países têm interesses convergentes, como em temas relativos ao comércio internacional (por exemplo, a luta pelo fim dos esquemas protecionistas dos países desenvolvidos, isto é, a liberalização, de fato, do comércio internacional, e não a manutenção de mecanismos que protejam os países desenvolvidos em detrimento dos em desenvolvimento) e aos fluxos internacionais de capital, os quais, quase que totalmente desregulamentados, vêm afetando ambas as economias nacionais em uma intensidade nunca antes vista.

Na pauta bilateral também evidenciam-se possibilidades de cooperação, em diversos setores. Constituindo-se em sociedades marcadas pela desigualdade social, Brasil e África do Sul podem aprender muito um com o outro, e até mesmo desenvolver conjuntamente projetos de interesse mútuo. O Brasil possui alguma experiência na difícil questão do crescimento desordenado de suas grandes cidades, conhecimento que poderia auxiliar os sul-africanos em uma questão que vem se intensificando rapidamente na África do Sul desde os anos 1990. Outro campo em que o Brasil está bem adiantado é no setor de saúde pública, mais especificamente com relação a doenças sexualmente transmissíveis. Como o problema é gravíssimo na África do Sul, o Brasil já ofereceu cooperação nessa área, sobretudo na questão da AIDS. Os sul-africanos, por sua vez, para citar um exemplo, acumularam conhecimentos especializados na área de mineração, os quais certamente seriam muito úteis ao Brasil. Há, também, boas perspectivas para a troca de informação e conhecimento no setor agrícola, em que um e outro desenvolveram tecnologias próprias e adaptáveis a ambas as realidades.

O comércio entre os dois países também cresce continuamente, mantendo o padrão histórico de crescimento gradual e constante verificado desde o início dos contatos comerciais. Mas o mais importante é que a pauta bilateral vem sofrendo alterações qualitativas nas últimas décadas, sendo já uma característica do passado o intercâmbio de produtos primários. Assim, o entrosamento é grande, particularmente, no setor automobilístico. A recém anunciada venda de aviões da Embraer (modelo ERJ-135) para a companhia sul-africana South Africa Airlink, em um negócio que pode chegar a US\$1 bilhão, é outro forte indicativo das grandes possibilidades comerciais que o Brasil possui na África do Sul.

Finalmente, não seria exagerado concluir que, após tantos desencontros entre os dois países, motivados por questões de princípio, de difícil arranjo político para sua superação, o relacionamento entre o Brasil e a África do Sul apresenta a tendência a um gradual crescimento justamente na última década do período cronológico em que se encerra a análise desenvolvida no presente trabalho. Com efeito, pela primeira vez no âmbito das vinculações históricas 


\section{entre ambos, não existem condicionamentos ideológicos ou outros de natureza exógena a dificultar ou impossibilitar um entendimento que se apresenta altamente profícuo para os dois países.}

Junho de 2001

\section{Notas}

1 A União Sul-Africana nasceu em 1910, da federação das antigas colônias do Cabo e de Natal e dos ex-Estados independentes de Orange e Transvaal, então colônias britânicas. Através de um referendo, a União Sul-Africana transformou-se em República em 1960, quando passou a denominar-se República da África do Sul. Em 1961, desligou-se da Commonwealth Britânica, assumindo para si a soberania plena e totalmente desvinculada da Grã-Bretanha. Neste trabalho os termos União Sul-Africana e República da África do Sul, ou, simplesmente, África do Sul, eqüivalem-se, salvo quando houver referência em contrário.

2 Pesou muito para a decisão brasileira de distanciar-se de Pretória o resultado do processo da descolonização dos territórios portugueses. O Império colonial português ruiu entre 1974 e 1975. Tal presença colonial em África inibia uma ação mais desenvolta da diplomacia brasileira, uma vez que o país não conseguiu manter-se afastado de todo dos desígnios portugueses em África, os quais se revelaram numa incômoda herança para a diplomacia brasileira administrar no continente africano.

3 Report by Alwyn Zoutendyk on the Interchange of Trade between The Union of South Africa and South America Republics - Brazil; Argentine; Uruguay. Pretória, 18 th July, 1936, p.2. National Archives of South Africa (doravante NASA). caixa Buitelandse Sake (doravante BTS), 10/1/35, vol.1, Brazil - Union of South Africa - Comercial Relations.

Brasil. Ministério das Relações Exteriores. Relatório. Rio de Janeiro: Seção de Publicações da Divisão de Documentação do Ministério das Relações Exteriores, 1944, p.190. Doravante somente Relatório.

5 Muito embora o Ato de criação da União Sul-Africana (South African Act, de 1909) não reconheça autonomia total à União, esta gozava, com efeito, de alto grau de autonomia, possuindo parlamento próprio, primeiro ministro e governador geral, que representava a Coroa Britânica. Constituía, pois, um Estado unitário e em muito se diferenciava de uma colônia, razão pela qual se refere à União como "país”. Gradualmente, o governo da União Sul-Africana foi conquistando mais autonomia, até mesmo com relação à sua política externa, garantida pela Declaração Balfour, em 1926.

6 Informação recebida pela Professora Zélia Roelofse do Comandante A.L.du Preez, então Capitão do Exército sul-africano em atividade na Itália. Citado em: ROELOFSE, Zélia. “ Brazil - A lesson in national unity”. In: Unisa Latin American Report, 2(2), September 1986, p. 29.

7 O Acordo Comercial de 1939 foi proposto pela União Sul-Africana, e se estendia "aos produtos da União Sul-Africana e do Território do Sudoeste Africano sob seu mandato”, além de prever a cláusula da nação mais favorecida. Memorando DAF-II/75, assinado por Bernardo Pericás Neto, Chefe substituto da DAF-II. Brasília, 24 de novembro de 1977. AMRE, Memorandos/ Pareceres/Requerimentos, caixa F 01, 1977. Confidencial.

8 Decreto $n^{\circ} 23.943$ de 28/10/1947 - Artigo $1^{\circ}$ Fica criada a Legação do Brasil na União Sul Africana, com sede em Pretória. (In: Leis do Brasil, 1947, v. 8,p.57) p.7. Cf. BRASIL. Ministério das Relações Exteriores (Biblioteca). Missões Diplomáticas e Repartições 
Consulares - criação, transformação e extinção. Legislação atualizada até 31 de dezembro de 1966. Seção de Publicações, 1968.

9 Report by Alwyn Zoutendyk on the Interchange of Trade between The Union of South Africa and South America Republics - Brazil; Argentine; Uruguay. Pretória, 18 th July, 1936, p.2. National Archives of South Africa (doravante NASA). caixa Buitelandse Sake (doravante BTS), 10/1/35, vol.1, Brazil - Union of South Africa - Comercial Relations. Ver especialmente p. 2 a 8 .

10 Ibidem, p. 6-8.

11 Ibidem.

12 É relevante observar a contradição explícita entre o discurso de Osvaldo Aranha e a realidade política brasileira, haja vista que o país vivia em plena ditadura do governo Vargas. Ofício de M. E. Antrobus, Office of the High Comissioner for the United Kingdom. para H.D.J. Bodenstein, Secretário para Assuntos Externos. Cape Town, 27 de maio de 1938. NASA, BTS, caixa 72/10/ 1, Brazilian Legation in the Union (of South Africa).

13 Idem.

14 SCHELLNACK, Isabel S. Chile, South Africa and the great powers, 1795-1948. Pretória: University of South Africa, 1998, p. 134.

15 O governo do Marechal Eurico Gaspar Dutra se caracterizou, em certa medida, pelo alinhamento aos Estados Unidos e por uma expressiva política anticomunista, de acordo com os moldes da nascente Guerra Fria. Sobre a política externa daquele governo ver: MOURA, Gerson. $O$ alinhamento sem recompensa: a política externa do governo Dutra. Rio de Janeiro: CPDOC/ FGV, 1990.

16 Ver: GELDENHUYS, Deon. The diplomacy of isolation - South African foreign policy making. Nova York: St. Martin’s Press, 1984, p.4. Na Argentina e no Brasil, até 1947, as relações eram em nível consular.

17 No caso do Brasil, ocorreu a consolidação de uma tendência que vinha se cristalizando desde pelo menos o início dos anos 1930, qual seja: a substituição da Grã-Bretanha pelo Estados Unidos da América como o principal parceiro do Brasil, tanto em termos econômicos quanto de influência política e cultural. Pedro Malan discute a inserção econômica internacional brasileira em seu clássico trabalho: MALAN, Pedro. "Relações Econômicas Internacionais do Brasil (1945-1964)”. In: FAUSTO, Boris (org.). História geral da civilização brasileira. São Paulo: Difel, 1986, t. 3, v. 4, p.51-106.

18 É de se notar que a grande maioria dos teóricos que se dedicaram ao estudo da geopolítica e aos seus reflexos para o futuro do Brasil eram oriundos das forças armadas, muitas vezes ainda na ativa. Assim, tal característica reforça o papel influente de tais teóricos durante o regime militar, uma vez que se tratava da aplicação ou, no mínimo, discussão, de pensamentos elaborados por “companheiros de armas”, muitas das vezes em plena atividade. Dentre os oficiais que mais se destacaram no estudo da geopolítica e suas implicações para o Brasil pode se citar: no Exército, o General Golbery do Couto e Silva, que escreveu a obra Geopolítica do Brasil. Rio de Janeiro: José Olympio, 1967. Na Marinha destacou-se o Almirante Carlos de Meira Mattos. De suas obras citamos: Projeção Mundial do Brasil. São Paulo: Leal, 1961; Brasil: geopolítica e trópicos. Rio de Janeiro: Bibliex, 1984; Brasil - geopolítica e destino. Rio de Janeiro: José Olympio, 1977; “O Atlântico Sul - sua importância estratégica”. A Defesa Nacional, 688, 1980, p.73-90.

19 OTAS, abreviatura para Organização do Tratado do Atlântico Sul. Iniciativa sul-africana tendo em vista a criação de um Pacto Militar para defesa do Atlântico Sul e que continha, em sua formulação, a idéia subjacente de romper o isolamento político e diplomático que vinha sendo imposto à África do Sul em decorrência da política de segregação racial, ou apartheid. O Brasil chegou a ser incluído entre os países a serem alvos de represálias nas recomendações da Conferência 
de Dar-Es-Salaam, quando foi, para efeitos de sanções diplomáticas e econômicas, colocado ao lado de Portugal, África do Sul, França, Grã-Bretanha, Alemanha e Estados Unidos. Cf. Memorando DAO/12, assinado por Wladimir do Amaral Murtinho, Chefe do Departamento da África, Ásia e Oceania, para o Secretário Geral das Relações Exteriores. Brasília, 11 de fevereiro de 1974. AMRE, Memorandos, caixa C - 02, 1974. Confidencial.

20 O Brasil não permitia a venda de armas para a África do Sul desde meados da década de 1960. Contudo, armas leves, de defesa pessoal, ou para fins esportivos produzidas no país pelas empresas Rossi e Taurus, continuaram sendo exportadas para a África do Sul, sem o aval do governo brasileiro. O exportadores, na verdade, utilizavam-se de vários artifícios para promover esse comércio. Um deles era vender armas para empresas aparentemente registradas no Lesoto, mas geralmente inexistentes. Como o envio da mercadoria tinha que, necessariamente, passar pela África do Sul, a carga era desviada no aeroporto de Johannesburg, seu verdadeiro destino final.

21 Ofício de J. Van Dalsen, Secretário de Assuntos Externos, para Embaixada em Brasília. 11 de março de 1975. ADFA, Brazil Relations with South Africa, 1/10/3, vol. 7. Secreto.

22 Memorando DAF-II/52, para o Chefe da Divisão de África II. Brasília, 22 de outubro de 1979. AMRE, Memorandos, caixa H 01, 1979. Confidencial.

23 A propósito da participação da África do Sul na Associação dos Países da Margem do Índico, ver: BURROWS, David. "South Africa's role in the Indian Ocean Rim Initiative”. In: South Africa Yearbook of International Affairs, 1997, p.169-178.

24 Essa idéia já foi defendida por alguns intelectuais sul-africanos, mas aparentemente não empolgou a diplomacia da África do Sul. Ver: BROEKMAN, David O . "A South Atlantic Rim Association: from a notion to a reality?”. UNISA Latin American Report. 14 (2) July-December, 1998, p.4-20. STAHL, Heinz-Michael. "Prospects for co-operation between SADC and Latin American trade blocs.” UNISA Latin American Report. 14 (2) July-December, 1998, p.21-27.

25 Cf. Informação n 581 da Assessoria de Comunicação Social do Ministério das Relações Exteriores. 08 de dezembro de 2000. Disponível em: http://www.mre.gov.br/infocred/info581-00.htm

26 As estimativas para o número de pessoas infectadas vírus HIV na África do Sul variam muito. A mais otimista indica que cerca de $10 \%$ da população estaria infectada. A mais pessimista, e talvez realista, estima algo em torno de $30 \%$ da população. O mais grave, no entanto, é que o país carece de uma política pública voltada para o controle da epidemia através do esclarecimento da população. Não há, sequer, atendimento especializado acessível à população de baixa renda. Outro detalhe, de especial importância e que vem contribuindo para agravar a situação, é o fato de que o próprio Presidente Thabo Mbeki tentou “politizar” a discussão científica, manifestando suas sérias dúvidas se o HIV realmente é o causador da AIDS. Enquanto isso, sequer as mulheres grávidas têm direito a receber a medicação mundialmente utilizada para evitar a contaminação do filho e melhorar a qualidade de vida do doente, o AZT e o coquetel de remédios que acompanha a administração da droga. Essas informações foram colhidas através da leitura diária dos jornais sul-africanos, vivamente embalados na polêmica envolvendo os conhecimentos “científicos” do Presidente Thabo Mbeki, e através de conversas com cidadãos sul-africanos durante o período em que este autor passou na África do Sul como pesquisador visitante na Universidade da África do Sul, em Pretória.

27 Cf. Informação n 581 da Assessoria de Comunicação Social do Ministério das Relações Exteriores. 08 de dezembro de 2000. Disponível em: http://www.mre.gov.br/infocred/info581-00.htm

28 A EMBRAPA e a Agricultural Research Council assinaram em 1992 um "Memorando de Entendimento" visando à troca de técnicos entre os dois países. Interessa aos sul-africanos o conhecimento brasileiro no setor de produção de sucos de frutas. O Brasil, por sua vez, tem interesse na tecnologia sul-africana de irrigação por gotejamento, na produção de uvas e vinhos e criação de animais adaptados a climas semi-áridos. 
Resumo

O principal objetivo do artigo é analisar as relações entre o Brasil e a África do Sul em perspectiva histórica. Uma vez iniciadas, essas relações atravessaram três grandes fases. No primeiro momento, que foi de 1918 a 1947, prevaleceu o comércio como fator da aproximação, constituindo-se tal período em momento de encontros e descobertas mútuas. A segunda fase, de 1947 a 1991, foi marcada pelo estabelecimento de relações diplomáticas e pelo gradual distanciamento entre os dois países. A última grande fase vem sendo marcada pela reaproximação entre Brasília e Pretória, uma vez que foi removido o principal empecilho para a concretização de relações prósperas entre os dois países, ou seja, o fim da política de apartheid. Durante esse último período, iniciado com o processo de democratização da África do Sul no alvorecer da década de 1990, há o renascimento das relações, em um contexto em que se vislumbra a possibilidade do estabelecimento de uma parceria estratégica, que interessa diretamente aos dois países.

\section{Abstract}

The main purpose of this article is to study the diplomatic relations between South Africa and Brazil in a historical perspective. Bilateral relations between the two countries can be divided into three distinct phases. The first one, dating from 1918 to 1947, had trade as its core element and provided an opportunity for mutual discoveries. The second phase, from 1947 to 1991, was characterized by the establishment of full diplomatic relations followed by a gradual decrease in intensity of official interchange. The third phase can best be described as one of rapprochement between Brasilia and Pretoria, a direct consequence of the end of apartheid - the single most important obstacle to successful relations in prior years. A dynamic renewal of Brazilian and South African relations is therefore taking place in close association with the process of South African democratization throughout the 1990s, creating the context for mutually beneficial strategic partnership.

Palavras-chave: Brasil. África do Sul. Política Externa.

Key words: Brazil. South Africa. Foreign Policy 